\title{
Analysis of the development of students' physical and technical thinking at rural schools
}

\author{
G. A. Shyshkin*, K. M. Zykova, I. H. Kosohov \\ Berdyansk State Pedagogical University, Ukraine \\ *Corresponding author. E-mail: ur3qugs@gmail.com
}

Paper received 25.08.18; Accepted for publication 29.08.18.

https://doi.org/10.31174/SEND-PP2018-174VI72-06

\begin{abstract}
Article is devoted to the analysis of the study of the relationship between the level of development of technical thinking and the interest of students in the study of physics. The study used the Bennet test, which was a long-term tested and found a widespread use. Based on this test, the level of technical thinking of the students was assessed, in particular, their ability to read the drawings, to understand the schemes of technical devices and the principles of their work, to solve the simplest physical and technical problems.
\end{abstract}

Keywords: physical education, technical thinking, interest in the study of physics, motivation, quality of education.

Introduction. Physics is the scientific basis for the development of many fields of technics and technology, therefore, as a subject of study, it plays a leading role in polytechnic teaching of students. The content of physics as a subject of study represents a wide opportunity to familiarize students with the main areas of development of the main industries of production. Some branches of technology are directly related to physics. Equipment of machine-building, energy, light industry, medical equipment, etc. are operating by physical phenomena and laws.

The main tasks of polytechnic studies at the present stage of the development of a comprehensive school includes: familiarizing students with the scientific principles of modern production, instilling skills in handling the most common types of tools, development of creative scientific and technical thinking.

In the conditions of intensive development of technics and technology for the development of physical and technical thinking, students should pay special attention. Ukraine has a sharp shortage of specialists in the industrial sector. In connection with this, there is a need for a study of the state of polytechnic education of young people in terms of profile education. However, the formation of high-quality polytechnic knowledge can't be realized without the development of student's technical thinking.

Overview of publications on the topic. In our studies, we determined that the physical-technological model of a real object or process is based on the integration of the three world scenes, namely physical, technical, and scientific. After all, the technical picture of the world is based on the original philosophical provisions about the origin and nature of technology [1].

O. Gubenko researched the problem of the formation of high-level students' readiness to choose a profession in the field of creative technical activities. He noted that creating conditions for the activation and development of creative technical thinking is one of the most important means for forming the readiness of students to elect their technical professions. At the present stage of the society development, there has been an objective contradiction between the social orders for the education of a creative worker and the level of formation in the younger generation of readiness to choose occupations in the field of creative technical activities [2].

The development of technical thinking in teaching general engineering disciplines was considered by $\mathbf{M}$.
Bondar. The scientist studied the issues of developmental training of future specialists of the agricultural profile by means of general engineering disciplines. Also, the scientist analyzed psychological and pedagogical research on the problem of developmental education [3].

Development of technical thinking of students in the process of studying the drawing was considered by $\mathrm{G}$. Raykovskaya. Academician draws attention to the development of technical thinking in the process of graphic activity. To achieve this goal, it is necessary to consider this process as an effective tool for activating students' educational activities, which will enable the teacher to make the learning process interesting and creative [4].

The purpose of article. To make an analysis of our study of the relationship between the development of technical thinking and the level of interest of students to the study of physics and their comparison.

Materials and methods. First of all, the basis of the formation of technical knowledge is technical thinking. Currently, there are three main types of technical thinking. We refer to them: everyday (non-scientific), classical (scientific) and modern (scientific, dialectical in nature technical thinking).

Modern type of technical thinking and its corresponding technical knowledge presupposes knowledge of the subject in the cognitive process; the dependence of the obtained results on the tools used in cognition and the vectors of their application; statistically probabilistic nature of the results obtained, etc.

To analyze the level of development of technical thinking of students, we used the Bennet test to assess the level of development of technical thinking, which has been repeatedly tested. This test is intended to assess the technical thinking of human, in particular - its ability to read the drawings, understand the schemes of technical devices and the principles of their work, solve the simplest physical and technical problems.

The questionnaire was conducted among the students of the VIII-XI classes of rural schools. The test contained 70 technical drawings with tasks and variants of possible answers to them. The essence of the tasks was to find the right answer to each of the drawings.

Results and their discussion. For each correct test, the student received the first ball. The total sum of points, scored by student made it possible to conclude the level of development of students' technical thinking. Depending 
on the number of student-grade points, we have identified five levels of technical thinking that consisted of: very

high, high, medium, low, very low (Table 1).

Table 1. Levels of development of technical thinking among rural school students

\begin{tabular}{|c|c|c|c|c|c|}
\hline \multirow{2}{*}{$\begin{array}{c}\text { Student } \\
\text { groups }\end{array}$} & \multicolumn{4}{|c|}{ Levels of development of technical thinking (abilities to technical activity) } \\
\cline { 2 - 6 } & very low & low & medium & high & very high \\
\hline Boys & Less 26 points & 27-32 points & 33-38 points & 39-47 points & More than 48 points \\
Girls & Less 17 points & $18-22$ points & 23-27 points & $28-34$ points & More than 35 points \\
\hline
\end{tabular}

In total, 186 students of rural schools took part in the research. Among them, there are 80 boys and 106 girls.

Test results showed that the highest percentage of students have a rather high level of development of technical thinking. It ranges from 31 to $39 \%$ of the number of all students in grades VIII-XI who took part in the testing. The very low level ranged from $2 \%$ to $4 \%$ of the students polled, the lowest - from $11 \%$ to $18 \%$, medium - from $21 \%$ to $36 \%$, very high - from $15 \%$ to $29 \%$ (Fig. 1 ). This division is explained by the fact that students at rural schools are faced with agro-industrial equipment and are watching their work more often than students at urban schools.

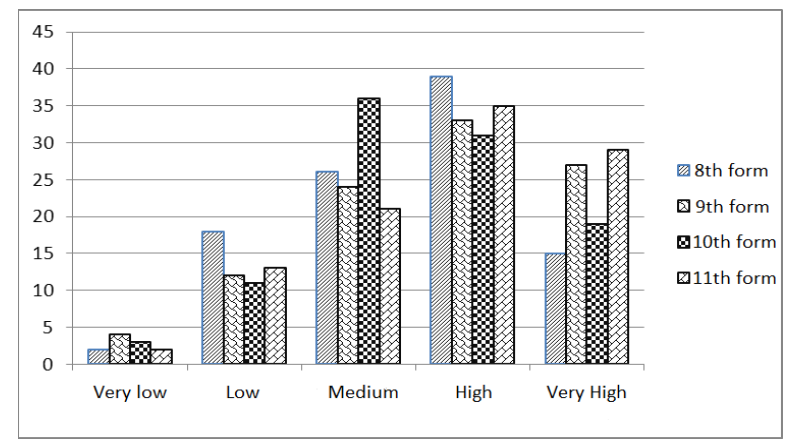

Figure 1. Analysis of the results of testing the level of development of technical thinking of students at rural schools

If we compare the results of the test of boys and girls, then we'll see the next such a picture (Fig. 2). In general, the results are similar to the first schedule, but the boys have a higher percentage of high level of technical thinking. Very low levels make up $1 \%$ and $3 \%$ respectively for boys and girls. The low level is $13 \%$ and $15 \%$, the medium is $26 \%$ and $29 \%$, the high is $39 \%$ and $35 \%$, the high is $21 \%$ and $18 \%$.

The next step in our study was to identify the level of self-interest of students in their interest in the subject "Physics". Students were asked to answer the questions of three types of questionnaires for identification: interest in the study of physics; the influence of knowledge on physics on the formation of practical knowledge and skills; the level of formation of skills in technical design.

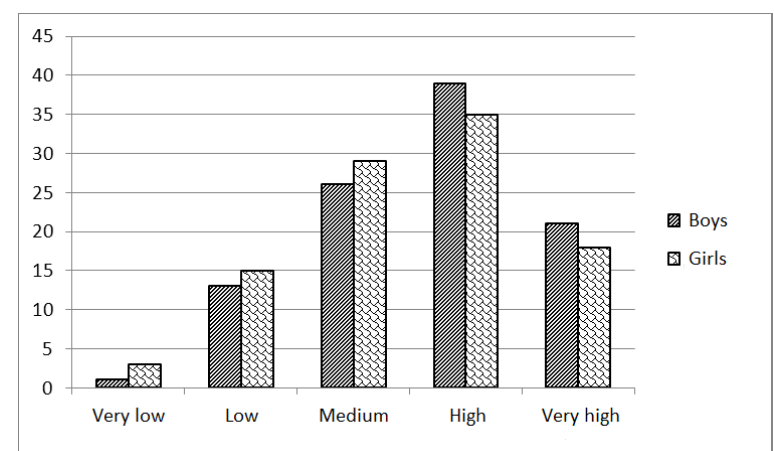

Figure 2. Analysis of the results of testing on the technical thinking of boys and girls of rural school
The results of the questionnaire for students of the VIII-XI classes in order to determine their level of interest in the study of physics is shown in Figure 3. Answers were evaluated on a ten-point scale (0 to 9$)$. For more convenient presentation of the research results, the points scored were conventionally divided into three levels: low (from 0 to 3), medium (from 4 to 6 ) and high (from 7 to 9).

At low level, $42 \%$ of the respondents assessed their interest in the study of physics, $48 \%$ on the medium, and $10 \%$ on the high level. That is, half of the students have an average interest in physics as a subject, while the other half have low. If we compare the interest of students studying in agrarian professional colleges, then there we see another picture - the vast majority have a medium interest in the study of physics, although a high level of interest is $9 \%$ [5].

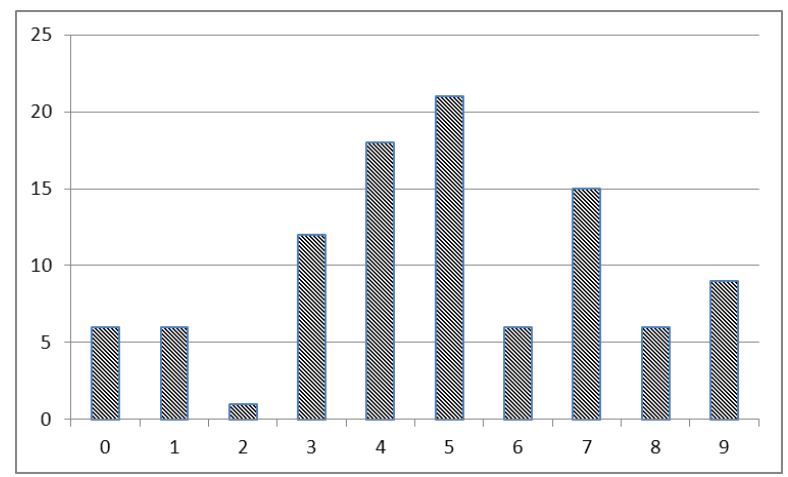

Figure 3. Analysis of the level of interest of students in the study of physics in rural schools

If we analyze the distribution of students by the levels of interest in the study of physics among boys and girls, then we have the following results (Fig. 4).

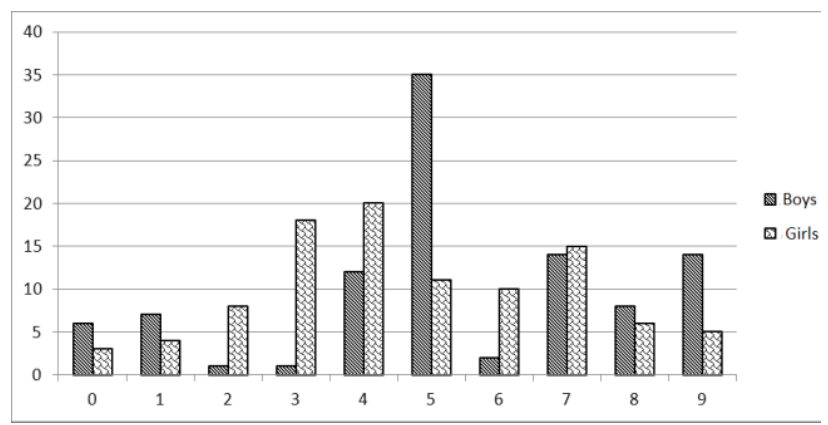

Figure 4. Analysis of the level of boys' and girls' interest in the study of physics

The guys have a low interest in physics $-15 \%$, medium $-49 \%$, high $-36 \%$. Girls have a low level of $33 \%$, a medium of $41 \%$, a high of $26 \%$. One can conclude that boys are more interested in the study of physics, considering the medium level is greater by $8 \%$, and the highest by $10 \%$. 
The next step in our research was to find out the students' view of the influence of knowledge on physics on the formation of practical skills. The results of the survey showed that students do not quite understand the role of physics in everyday life of a person. As the low level, the role of physics in the formation of practical skills was estimated by $49 \%$ of students, on medium $-48 \%$, high $3 \%$ (Fig. 5).

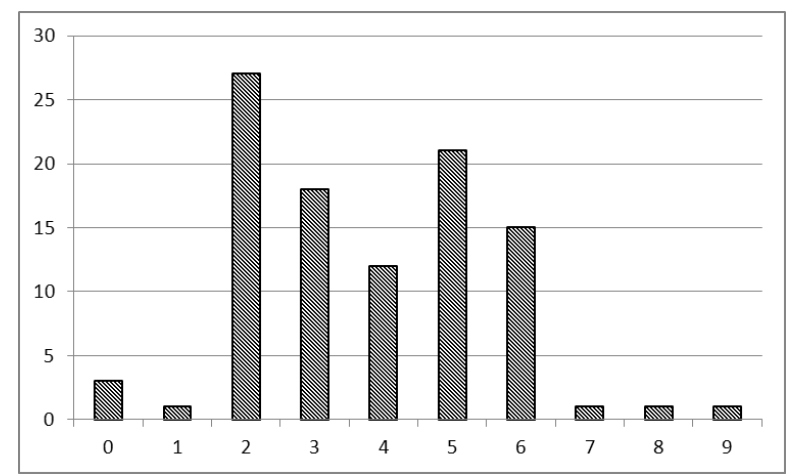

Figure 5. Analysis of pupils' assessment of the influence of knowledge on physics on the formation of practical knowledge and skills

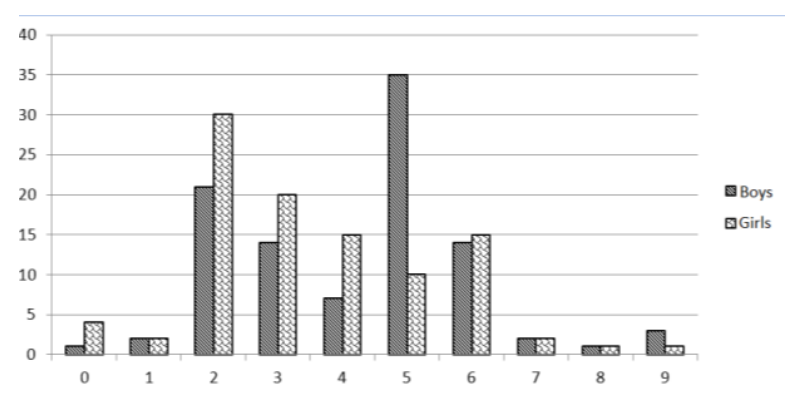

Figure 6. Analysis of students' assessment of the role of physics in the formation of practical knowledge and skills by boys and girls

If we compare the results of the questionnaire survey of boys and girls on their assessment of the impact of knowledge on physics on the formation of practical skills, then we have the following results. Boys' low level of assessment is $-38 \%$, medium $-56 \%$, high $-6 \%$. Girls have the low level by $56 \%$, medium $-40 \%$, high $-4 \%$ (Fig.6). That is, boys are more aware of the significance of physics in everyday life of a person and its influence on the development of industry.

Analysis of students' self-esteem results regarding their interest in technical design, showed that $42 \%$ of students did not show interest in this type of creative activity; at medium level, $48 \%$ of respondents expressed their interest in technical creativity, and $10 \%$ at high level.

A comparative analysis of boys' and girls' answers on the question of assessing their level of interest in technical design showed the following results. Boys' low level of assessment is $29 \%$, medium $-56 \%$, high $-27 \%$. Girls have the low level by $55 \%$, medium $-36 \%$, high $-9 \%$ (Fig.7).

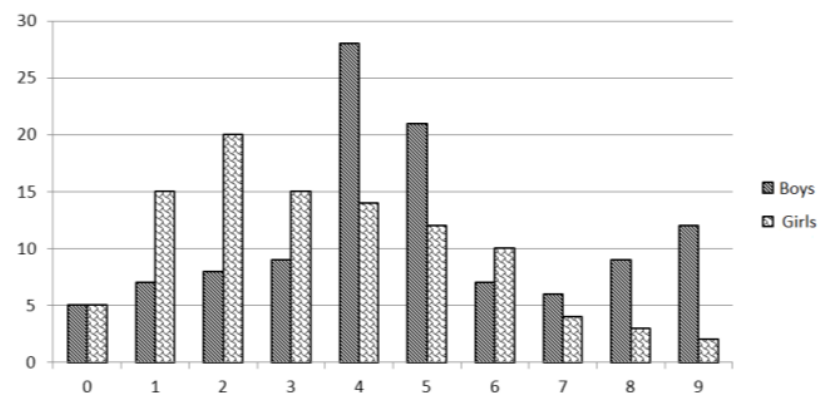

Figure 7. Analysis of the self-assessment boys' and girls' level of interest in technical design

Conclusions. The study of the development of technical thinking by students of rural general education institutions, conducted by us, showed that it has, in general, a medium level. If we compare the results of the test of boys and girls, then we see that the boys have a higher percentage of high level of technical thinking. At the same time, students do not quite understand the role of physics in human life and the formation of practical knowledge. Further researches needs the improving the methods of developing the technical thinking of students of general education institutions in the conditions of profile education and inducing them to actively physical and technical creative activities in the study of physics.

\section{REFERENCES}

1. Shyskin G.A. Methodical system of formation of integrated knowledge in physics in the system of training of technology teachers: monograph / Gennadiy Oleksandrovych Shyshkin. Donetsk: LANDON-XXI, 2014. - $365 \mathrm{~s}$.

2. Gubenko O. V. Formation of readiness for senior pupils to choose a profession in the sphere of creative technical activity: psychological aspect: avtoref. dis. na zdobuttya nauk. stup. kand. psikhol. nauk: 19.00.07 «Teoriya vikhovannya» / O. V. Gubenko. - K., 1998. - 24 s.

3. Bondar M.M. Development of creative technical thinking in the teaching of general engineering disciplines /
M.M. Bondar // Inzheneriia pryrodokorystuvannia. - 2014. №. 2. - S. 129-131.

4. Raikovska G. O. Development of technical thinking of students in the process of studying the drawing: dys. kand. ped. nauk: 13.00.02 / Г. O. Raikovska. - K., 2003. - 219 c.

5. Zykova K.M. Analysis of cognitive activity of students of professional colleges during the study of physics / K.M. Zykova, I.G. Kosogov, G.A. Shyskin // Zbirnyk naukovykh prats. Seriia: Pedahohichni nauky. - Vypusk LXXV. Tom 1. - Kherson: Vydavnychyi dim «Helvetyka», - 2017 S. $122-125$. 